OPEN ACCESS

Edited by:

Mika Tada,

Tohoku Institute of Technology, Japan

Reviewed by:

Venkat R. Pannala,

DoD, Biotechnology HPC Software

Applications Institute, United States

Omar Borsani

University of the Republic, Uruguay

${ }^{*}$ Correspondence:

Michaela Sedlářová

michaela.sedlarova@upol.cz

Specialty section:

This article was submitted to

Oxidant Physiology,

a section of the journal

Frontiers in Physiology

Received: 31 July 2017 Accepted: 06 October 2017 Published: 24 October 2017

Citation:

Sedlářová M and Luhová L (2017) Re-Evaluation of Imaging Methods of

Reactive Oxygen and Nitrogen

Species in Plants and Fungi: Influence

of Cell Wall Composition.

Front. Physiol. 8:826.

doi: 10.3389/fphys.2017.00826

\section{Re-Evaluation of Imaging Methods of Reactive Oxygen and Nitrogen Species in Plants and Fungi: Influence of Cell Wall Composition}

\author{
Michaela Sedlářová ${ }^{*}$ and Lenka Luhová ${ }^{2}$ \\ ${ }^{1}$ Department of Botany, Faculty of Science, Palacký University Olomouc, Olomouc, Czechia, ${ }^{2}$ Department of Biochemistry, \\ Faculty of Science, Palacký University Olomouc, Olomouc, Czechia
}

Developmental transitions and stress reactions in both eukaryotes and prokaryotes are tightly linked with fast and localized modifications in concentrations of reactive oxygen and nitrogen species (ROS and RNS). Fluorescent microscopic analyses are widely applied to detect localized production of ROS and RNS in vivo. In this mini-review we discuss the biological characteristics of studied material (cell wall, extracellular matrix, and tissue complexity) and its handling (concentration of probes, effect of pressure, and higher temperature) which influence results of histochemical staining with "classical" fluorochromes. Future perspectives of ROS and RNS imaging with newly designed probes are briefly outlined.

Keywords: confocal microscopy, fluorescent probes, reactive oxygen species, reactive nitrogen species, cell wall

\section{PAST AND PRESENCE OF FLUORESCENT PROBES FOR LOCALIZATION OF REACTIVE OXYGEN AND NITROGEN SPECIES}

Reactive oxygen species (ROS) are generated and scavenged over the whole life span of all known types of aerobic organisms. In plants and fungi production of ROS, together with reactive nitrogen species (RNS), has been linked with almost all developmental processes from germination through reproduction until cell death (Asada, 2006; Blokhina and Fagerstedt, 2010). ROS and RNS represent two classes of highly reactive signaling compounds indispensable also for stress reactions to extreme environmental factors, pathogens, or injuries (Wojtaszek, 1997; Qiao et al., 2014; Del Río, 2015; Dietz et al., 2016; Sedláŕová et al., 2016; Raja et al., 2017). In spite of extensive studies, metabolism of both ROS forms, i.e., molecular $\left(\mathrm{H}_{2} \mathrm{O}_{2}\right.$, hydrogen peroxide; ${ }^{1} \mathrm{O}_{2}$, singlet oxygen) and free radicals $\left(\mathrm{O}_{2 \bullet}^{-}\right.$, superoxide anion; $\mathrm{OH}_{\bullet}$, hydroxyl radical; $\mathrm{HO}_{2}$, perhydroxy radical; $\mathrm{RO}$ •, alkoxy radicals), and $\mathrm{RNS}$ ('NO, nitric oxide; $\mathrm{ONOO}^{-}$, peroxynitrite; and others) still has not been completely understood. Quite recently, peroxynitrite (formed upon NO reaction with superoxide anion) was shown as a positive regulator of plant cell signaling by tyrosine nitration in proteins (Vandelle and Delledonne, 2011) and tightly linked to necrotrophic phase of oomycete pathogenesis (Arasimowicz-Jelonek et al., 2016). ROS and NO-mediated signaling is tightly connected with molecules influencing normal ontogeny, acclimation, and pathophysiology, including multiple hormones, enzymes, and genes (Gill and Tuteja, 2010; León et al., 2014; Nie et al., 2015; Saxena et al., 2016; Raja et al., 2017).

Abbreviations: CW, cell wall; DHDCF DA, 2',7'-dichlorodihydrofluorescein diacetate; DAF-FM DA, 4-amino-5-(Nmethylamino)-2' $7^{\prime}$-difluorofluorescein diacetate; RNS, reactive nitrogen species; ROS, reactive oxygen species; SOSG, Singlet Oxygen Sensor Green. 
Timing of generation, degradation, and diffusion of ROS and RNS within different cellular compartments have therefore attracted attention in many model organisms (Del Río, 2015; Considine et al., 2017). Cross-talk of ROS and RNS has been pointed out also in peroxisomes (Corpas et al., 2017) and signal transduction to other organelles, e.g., mitochondria, Golgi, and endoplasmic reticulum, has been shown (Wanders et al., 2016).

Methods for ROS/RNS detection in plant material based on histochemical staining, e.g., with 3,3'-diaminobenzidine (DAB) for hydrogen peroxide (Thordal-Christensen et al., 1997) or nitro blue tetrazolium chloride (NBT) for superoxide (Jabs et al., 1996), are still being applied for stereomicroscopy and light microscopy, esp. in Arabidopsis research. Cell-permeable fluorescence-based probes were subsequently introduced to detect tiny real-time changes in ROS and RNS levels within relevant cellular compartments, e.g., DCF DA and DHDCF DA for detection of ROS (Kehrer and Paraidathathu, 1992; Hempel et al., 1999), DAF-2 DA and DAF-FM DA for NO (Kojima et al., 1999; Lombardo et al., 2006), or SOSG for singlet oxygen (Flors et al., 2006; Kim et al., 2013). A wide range of ROS and NO targeted fluorescent probes has been marketed but some of the most commonly used ones were found to suffer from low selectivity and specificity toward the analyte (e.g., DHDCF DA) or from photosensitization during incubation and microscopy (e.g., SOSG). In order to minimize artifacts, a sample staining in dark and visualization by (multiphoton) confocal microscopy has been advised. Nevertheless, fluorochromes able to cross plasma membrane (e.g., in diacetate form) which can be loaded into cells just by placing the samples (cells, tissues) into a solution of the dye significantly simplified ROS and RNS in vivo monitoring and enabled expansion of these techniques within plant science community. Considering the use of proper controls (e.g., ROS/RNS donors for positive controls, and ROS/RNS scavengers for negative ones), proper sample washing, keeping constant time of staining/scanning within a set of experiments, using optimal $\mathrm{pH}$ and turgor pressure can contribute to obtaining of correct results. Still it should be emphasized that histochemical staining and subsequent microscopic detection cannot be used for accurate ROS/RNS quantification but the combinations of several different analytical methods can give more reliable estimation of their intracellular levels (Gupta and Igamberdiev, 2013).

Optimization of staining procedures for different photosynthetic and fungal organisms in our laboratory showed that results of ROS/RNS imaging in multicellular biological matrices are significantly influenced by the feasibility of material infiltration with the applied probes (Figure 1). Current studies unveiled cell wall (CW) as a dynamic structure able to adapt to various conditions of growth, development, and environmental stresses; together with plasma membrane and periplasmic space, it regulates the flow of molecules into and out of the cell (Lesage and Bussey, 2006). The relative composition of polysaccharides, phenolic compounds, and proteins in $\mathrm{CW}$ varies among species and cell types, and changes with their developmental stage (Popper et al., 2011, 2014; Ochoa-Villarreal et al., 2012). In addition, stress factors induce CW reinforcement, such as deposition of lignin or callose in plant-pathogen interactions (Prats et al., 2008; Sedlářová et al., 2011; Miedes et al., 2014). Similarly, materials deposited either intercellularly or in tissue exterior (e.g., cutin and suberin, polyesters which function as permeability barriers to the movement of water) influence the penetration rate of used fluorescence probes. Our extensive experience, based on optimizing incubation conditions for different materials, combined with literary data resulted in Table $\mathbf{1}$ which summarizes cell wall composition in photosynthetic and fungal organisms together with comparison of concentrations used for ROS/RNS imaging with three commonly used probes (DHDCF DA, DAF-FM DA, and SOSG). Optimal experimental conditions (incubation time, temperature, probe concentration) differ among various model phototrophic organisms (higher plants, algae, and cyanobacteria), fungi and "fungi-like" organisms (oomycetes; Table 1). Although, the unicellular structures [protoplasts (Figure 1CI), pollen (Figure 1CIV), green algae, and thinwalled spores (Figure 1CII)] can be stained easily in general the probe concentration must be increased and incubation time prolonged for cyanobacteria, which are characterized by higher cross-linking of polysaccharides in the cell wall and production of external mucoid sheath (Hoiczyk and Hansel, 2000). For unicellular cyanobacterium Synechocystis, widely used photosynthetic model, the concentration of SOSG was increased from commonly used $50 \mu \mathrm{M}$ up to $250 \mu \mathrm{M}$ together with incubation temperature increased from room temperature to $37^{\circ} \mathrm{C}$ (Sinha et al., 2012). Relatively easy staining and imaging can be achieved on agar media (Figure 1A) for germinating fungi (Figure 1CII) and some oomycetes but also for plant pollen (Figure 1CIV) and small seeds. Higher concentrations of probes are advisable for plant tissues (Table 1; Figures 1CIII,V,VI). Excised leaves uptake the probes by xylem transport but longer periods of such incubations are inappropriate for most fluorochromes (Figure 1B). Natural openings like stomata (which represent $\sim 1 \%$ of leaf blade epidermal cells, 50$300 / \mathrm{mm}^{2}$ ), hydatodes (at leaf edge), or nectaria (in flowers) can enhance the introduction of fluorochromes into the living tissues of above-ground plant organs. The fluorochromes uptake in multicellular organs can thus be enhanced by increased external or decreased internal pressure, e.g., by syringe or vacuum infiltration, respectively (Figure 1B). Moreover, cutting tissue into pieces significantly increases penetration rates (Figures 1CV,VI) but several layers of mechanically injured cells on the cutting edge must be omitted from the evaluation (Prasad et al., 2017).

\section{DAWN OF RELIABLE ROS AND RNS IMAGING?}

Recognized drawbacks of commercially available fluorescence probes for ROS and RNS detection initiated a quest for improved tools to measure more accurately the differential in vivo patterns of ROS and RNS abundance within plant organs and meristems. Newly synthesized probes with increased specificity and improved photostability have been reported, such as Aarhus Sensor Green preferable to SOSG for singlet oxygen 
A

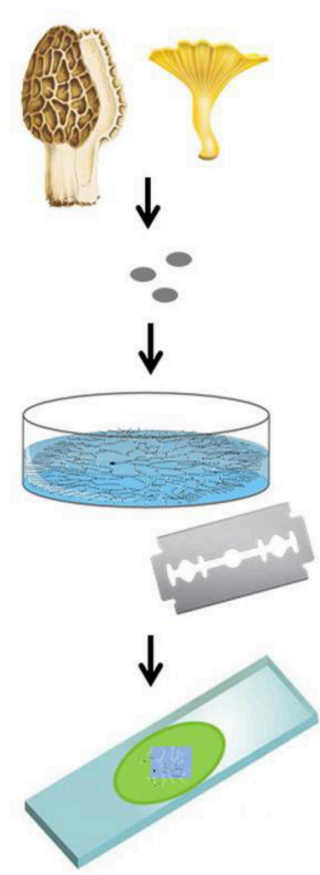

B
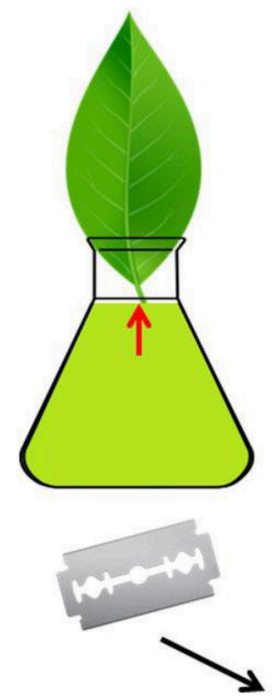

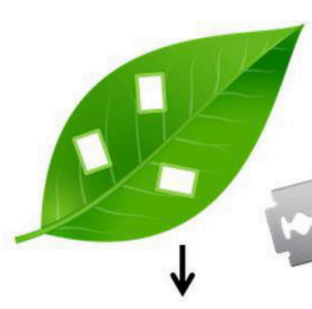

win

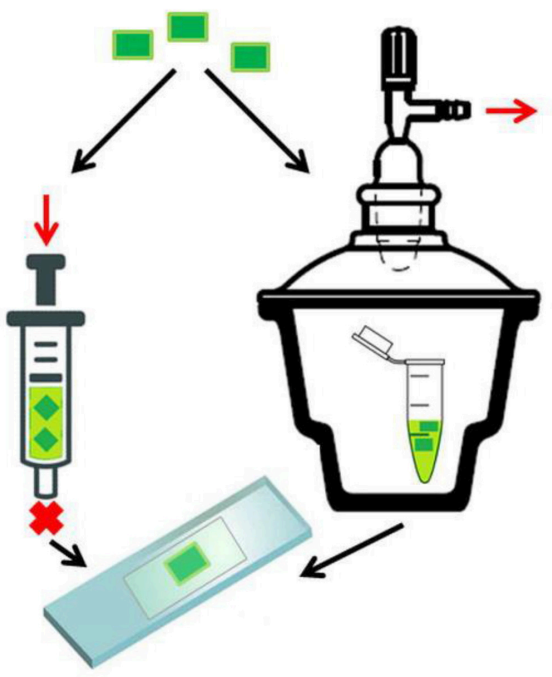

C
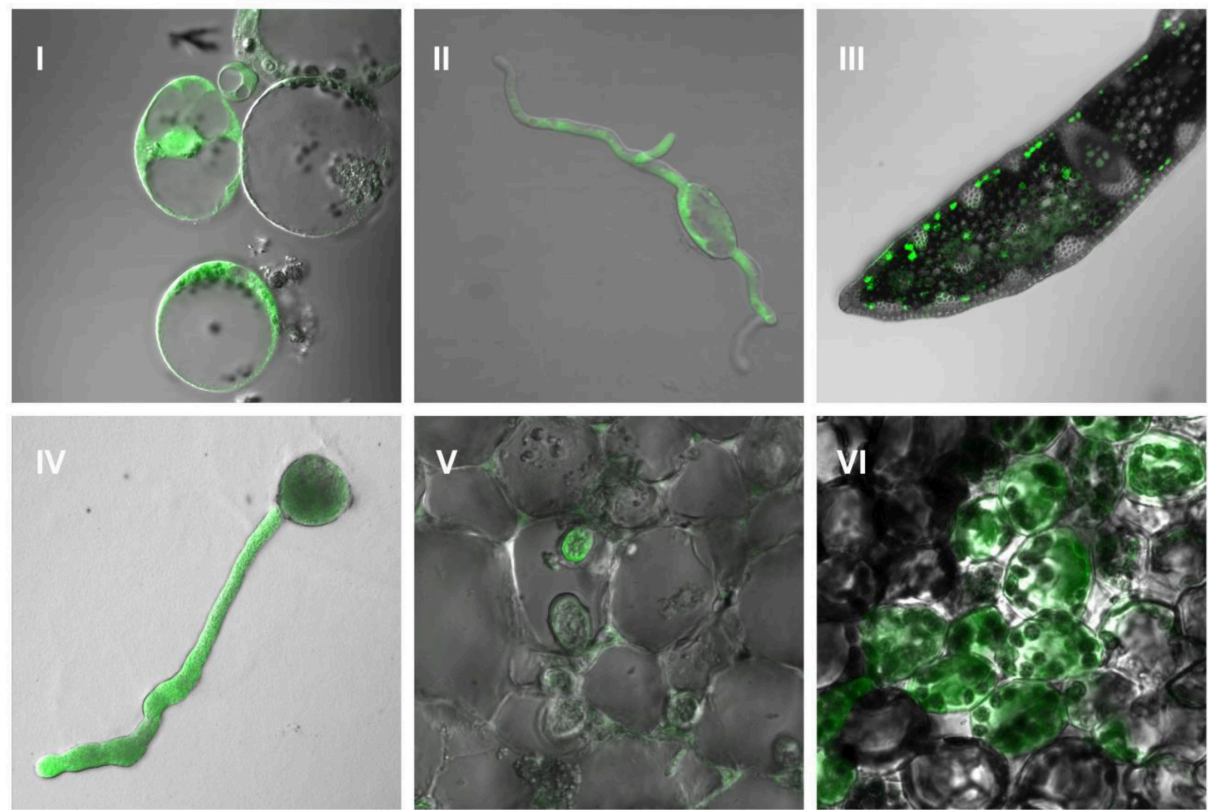

FIGURE 1 | Histochemical detection of ROS and NO with fluorescent probes. (A) ROS and RNS in fungi and oomycetes grown on agar can be stained and visualized directly on the medium. (B) ROS and RNS in plant tissues and phytopathogenic oomycetes or fungi can be stained by up-loading the probes to excised leaves by xylem transport or to small pieces of tissue using syringe or vacuum infiltration. (C) ROS and RNS detection (green signal) by confocal microscopy in different samples: (I-III) ROS detection by DHDCF DA in (I) cucumber protoplast $4 \mathrm{~h}$ after release $(10 \mu \mathrm{M}, 10 \mathrm{~min})$, (II) $8 \mathrm{~h}$ germinated conidia of Morchella conica (20 $\mu \mathrm{M}$, $15 \mathrm{~min})$, (III) in mesophyll cells of date palm leaf cross section during drought stress ( $20 \mu \mathrm{M}, 10 \mathrm{~min}) ;$ (IV,V) NO production localized by DAF-FM DA in (IV) $2 \mathrm{~h}$ germinated cucumber pollen ( $10 \mu \mathrm{M}, 30 \mathrm{~min})$ and (V) haustoria of Plasmopara halstedii infecting sunflower stem mesophyll cells (20 $\mu \mathrm{M}, 30 \mathrm{~min})$; (VI) singlet oxygen visualization with SOSG during mechanical injury of mesophyll cells of Arabidopsis thaliana cv. Columbia-0 (50 M, 30 min) (M. Sedlářová). 


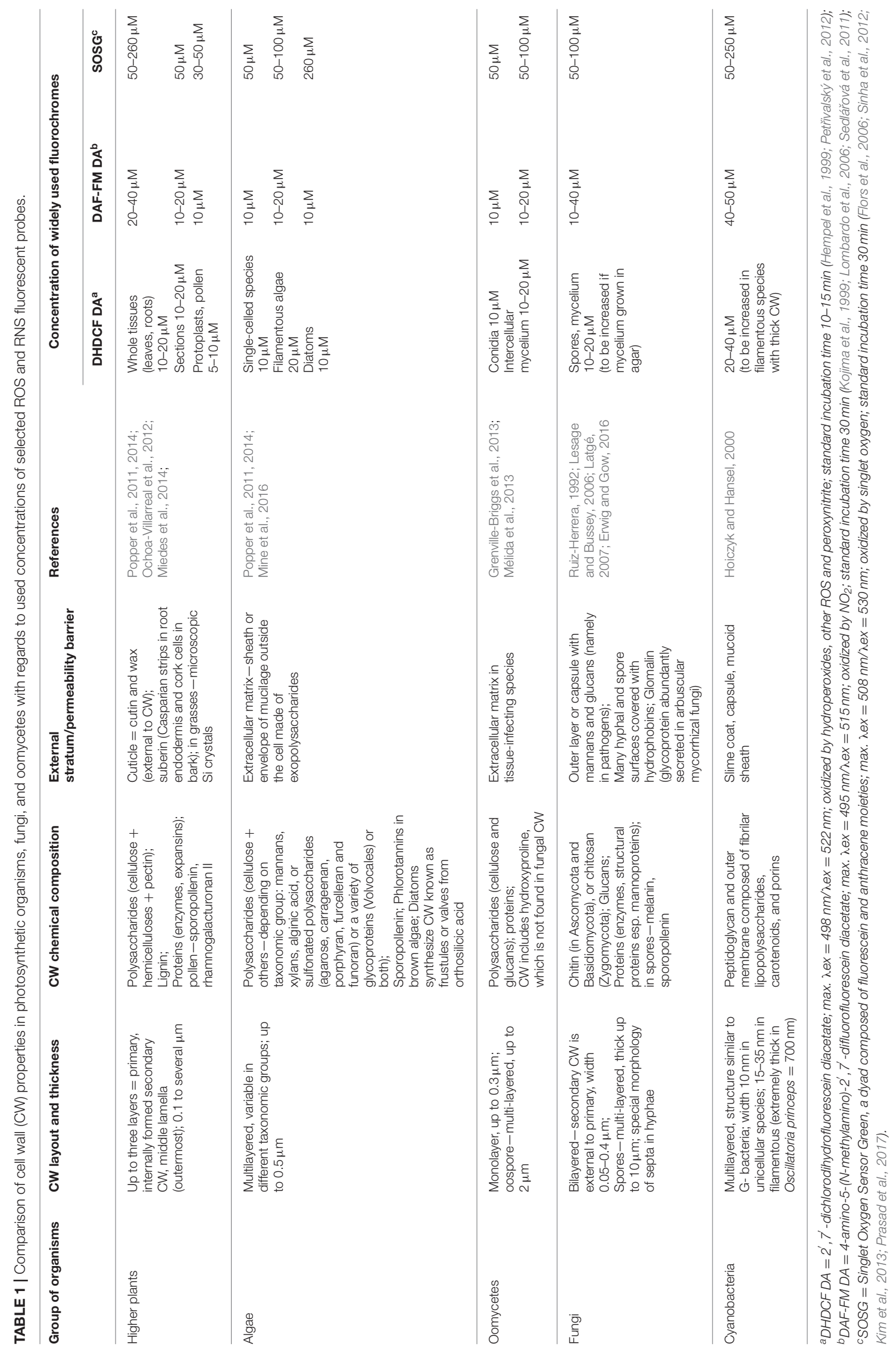


(Pedersen et al., 2014), but these are for various reasons of limited availability to users. Therefore, the need for further development of improved probes that can image individual endogenous ROS and RNS still continues. Recently, a new family of o-hydroxyamino-triarylpyrylium salts-based probes for NO detection was reported (Beltrán et al., 2014). A new fluorescent probe ContPY1 was prepared for investigations of hydrogen peroxide and tested in Arabidopsis, both on cultured cells and on leaves (Ledoux et al., 2013). Also, a single fluorescent probe, capable of simultaneous monitoring of both $\mathrm{NO}$ and $\mathrm{H}_{2} \mathrm{O}_{2}$ endogenously produced in living macrophages (Yuan et al., 2012) was synthesized. However, similarly to genetically encoded fluorescence proteins applicable for ROS monitoring (Schmitt et al., 2014) or immuno-spin traping (Mason, 2016), it has not yet been successfully applied to plant research.

Fluorescein derivatives have become replaced in animal ROS and RNS research by more specific molecular probes based on nanoparticles or redox-sensitive fluorescent proteins (for review see Guo et al., 2014; Peteu et al., 2014). As an example, the entirely new probe PAM-BN-PB (composed of three functional parts: phenanthroimidazole, benzonitrile, and phenyl boronate) was designed to detect $\mathrm{H}_{2} \mathrm{O}_{2}$ with good selectivity based on intramolecular charge transfer (Chen et al., 2017), and tested on human and animal cells and in vitro. However, the "classical fluorescent probes" based mainly on diaminofluorescein derivatives, still represent important tools to study ROS and RNS in plant science (Nie et al., 2015; Figure 1C). This can be partly attributed to more demanding protocols due to presence of $\mathrm{CW}$ and other extracellular matrices (Table 1) influencing the uptake of "new generation" probes. Encapsulating fluorescent probes into nanoparticles was reported to improve their stability, such as in peroxalate nanoprobe undergoing a three-component chemiluminescence reaction between $\mathrm{H}_{2} \mathrm{O}_{2}$, peroxalate esters, and fluorescent dyes as published for in vivo imaging of $\mathrm{H}_{2} \mathrm{O}_{2}$ in mouse model (Lee et al., 2007). Near-IR probes have been lately incorporated into polymeric micelles modified with animal cell-penetrating

\section{REFERENCES}

Arasimowicz-Jelonek, M., Floryszak-Wieczorek, J., Izbianska, K., Gzyl, J., and Jelonek, T. (2016). Implication of peroxynitrite in defence responses of potato to Phytophthora infestans. Plant Pathol. 65, 754-766. doi: 10.1111/ppa.12471

Asada, K. (2006). Production and scavenging of reactive oxygen species in chloroplasts and their functions. Plant Physiol. 141, 391-396. doi: 10.1104/pp.106.082040

Beltrán, A., Isabel Burguete, M., Abanades, D. R., Perez-Sala, D., Luis, S. V., and Galindo, F. (2014). Turn-on fluorescent probes for nitric oxide sensing based on the ortho-hydroxyamino structure showing no interference with dehydroascorbic acid. Chem. Commun. 50, 3579-3581. doi: $10.1039 / \mathrm{c} 3 \mathrm{cc} 49555 \mathrm{~h}$

Blokhina, O., and Fagerstedt, K. V. (2010). Reactive oxygen species and nitric oxide in plant mitochondria: origin and redundant regulatory systems. Physiol. Plant. 138, 447-462. doi: 10.1111/j.1399-3054.2009.01340.x

Chen, Y., Shi, X., Lu, Z., Wang, X., and Wang, Z. (2017). Fluorescent probe for hydrogen peroxide in vivo based on the modulation of intramolecular charge transfer. Anal. Chem. 89, 5278-5284. doi: 10.1021/acs.analchem.6b04810

Considine, M. J., Diaz-Vivancos, P., Kerchev, P., Signorelli, S., AgudeloRomero, P., Gibbs, D. J., et al. (2017). Learning to breathe: developmental peptides, esp. for peroxynitrite imaging experiments (Tian et al., 2011). However, (nano)micelles uptake by fusion with the plasma membrane is hindered in plant and fungal cells and up-to-date protocols for the cell wall removal exert excessive oxidative stress to the plant cells (Petřivalský et al., 2012).

Although, a plethora of ROS and RNS sensing molecules have been designed, just a part of them has been confirmed experimentally to be suitable for ROS and RNS in vivo monitoring. The situation resembles a "population bottle-neck"; only a reduced number of protocols are applicable to ROS and RNS microscopy in plant and fungal models and thus these few remain fixed in routine practice for a substantial period. With increasing knowledge on the importance of localized and tiny intracellular redox fluctuations the quantitative and spatiotemporal analysis of ROS and RNS levels in plant and fungal cells is still highly challenging.

\section{AUTHOR CONTRIBUTIONS}

MS prepared manuscript based on long-lasting discussions and joint experiments with LL, it was approved and widely discussed by both authors.

\section{ACKNOWLEDGMENTS}

The work was supported by the Czech Ministry of Education, Youth, and Sports (MSM 6198959215) and Palacký University in Olomouc (IGA UP PrF-2017-001 and PrF-2017-016) with former students M. Rajnohová, M. Smažák, T. Tichá, Z. Drábková Trojanová, Z. Tulpová, and T. Válová involved in the experiments. Microorganisms shown in Figure 1 come from the collection UPOC, a part of the Czech National Programme on Conservation and Utilization of Microbial Genetic Resources Important for Agriculture (kindly provided by P. Hašler, P. Havránek, A. Lebeda, and B. Mieslerová). Many thanks to A. Prasad, M. Rác, and P. Pospíšil from Department of Biophysics (CRH, UP) for valuable discussions. phase transitions in oxygen status. Trends Plant Sci. 22, 140-153. doi: 10.1016/j.tplants.2016.11.013

Corpas, F. J., Barroso, J. B., Palma, J. M., and Rodriguez-Ruiza, M. (2017). Peroxisomes: a nitro-oxidative cocktail. Redox Biol. 11, 535-542. doi: 10.1016/j.redox.2016.12.033

Del Río, L. A. (2015). ROS and RNS in plant physiology: an overview. J. Exp. Bot. 66, 2827-2837. doi: 10.1093/jxb/erv099

Dietz, K.-J., Mittler, R., and Noctor, G. (2016). Recent progress in understanding the role of reactive oxygen species in plant cell signaling. Plant Physiol. 171, 1535-1539. doi: 10.1104/pp.16.00938

Erwig, L. P., and Gow, N. A. (2016). Interactions of fungal pathogens with phagocytes. Nat. Rev. Microbiol. 14, 163-176. doi: 10.1038/nrmicro. 2015.21

Flors, C., Fryer, M. J., Waring, J., Reeder, B., Bechtold, U., Mullineaux, P. M., et al. (2006). Imaging the production of singlet oxygen in vivo using a new fluorescent sensor, Singlet oxygen sensor green. J. Exp. Bot. 57, 1725-1734. doi: $10.1093 /$ jxb/erj181

Gill, S. S., and Tuteja, N. (2010). Reactive oxygen species and antioxidant machinery in abiotic stress tolerance in crop plants. Plant Physiol. Biochem. 48, 909-930. doi: 10.1016/j.plaphy.2010. 08.016 
Grenville-Briggs, L. J., Horner, N. R., Phillips, A. J., Beakes, G. W., and van West, P. (2013). A family of small tyrosine rich proteins is essential for oogonial and oospore cell wall development of the mycoparasitic oomycete. Fungal Biol. 117, 163-172. doi: 10.1016/j.funbio.2013.01.001

Guo, H., Aleyasin, H., Dickinson, B. C., Haskew-Layton, R. E., and Ratan, R. R. (2014). Recent advances in hydrogen peroxide imaging for biological applications. Cell Biosci. 4:64. doi: 10.1186/2045-3701-4-64

Gupta, K. J., and Igamberdiev, A. U. (2013). Recommendations of using at least two different methods for measuring NO. Front. Plant Sci. 4:58. doi: 10.3389/fpls.2013.00058

Hempel, S. L., Buettner, G. R., O’Malley, Y. Q., Wessels, D. A., and Flaherty, D. M. (1999). Dihydrofluorescein diacetate is superior for detecting intracellular oxidants: comparison with $2^{\prime}, 7^{\prime}$-dichlorodihydrofluorescein diacetate, 5(and 6)-carboxy-2 $2^{\prime}, 7^{\prime}$-dichlorodihydrofluorescein diacetate, and dihydrorhodamine 123. Free Radic. Biol. Med. 27, 146-159. doi: 10.1016/S0891-5849(99) 00061-1

Hoiczyk, E., and Hansel, A. (2000). Cyanobacterial cell walls: news from an unusual prokaryotic envelope. J. Bacteriol. 182, 1191-1199. doi: 10.1128/JB.182.5.1191-1199.2000

Jabs, T., Dietrich, R. A., and Dangl, J. L. (1996). Initiation of runaway cell death in an Arabidopsis mutant by extracellular superoxide. Science 273, 1853-1856. doi: $10.1126 /$ science. 273.5283 .1853

Kehrer, J. P., and Paraidathathu, T. (1992). The use of fluorescent probes to assess oxidative processes in isolated-perfused rat heart tissue. Free Radic. Res. Commun. 16, 217-225. doi: 10.3109/10715769209049175

Kim, S., Fujitsuka, M., and Majima, T. (2013). Photochemistry of singlet oxygen sensor green. J. Phys. Chem. B 117, 13985-13992. doi: 10.1021/jp4 $06638 \mathrm{~g}$

Kojima, H., Urano, Y., Kikuchi, K., Higuchi, T., Hirata, Y., and Nagano, T. (1999). Fluorescent indicators for imaging nitric oxide production. Angew. Chem. Int. Ed. Engl. 38, 3209-3212. doi: 10.1002/ (SICI) 1521-3773(19991102)38:21<3209::AID-ANIE3209>3.0.CO;2-6

Latgé, J. P. (2007). The cell wall: a carbohydrate armour for the fungal cell. Mol. Microbiol. 66, 279-290. doi: 10.1111/j.1365-2958.2007.05872.x

Ledoux, Q., Veys, P., Van Cutsem, P., Mauro, S., Lucaccioni, F., and Marko, I. E. (2013). Validation of the boronate sensor ContPY1 as a specific probe for fluorescent detection of hydrogen peroxide in plants. Plant Signal. Behav. 8:e26827. doi: 10.4161/psb.26827

Lee, D., Khaja, S., Velasquez-Castano, J. C., Dasari, M., Sun, C., Petros, J., et al. (2007). In vivo imaging of hydrogen peroxide with chemiluminescent nanoparticles. Nat. Mater. 6, 765-769. doi: 10.1038/nmat1983

León, J., Castillo, M. C., Coego, A., Lozano-Juste, J., and Mir, R. (2014). Diverse functional interactions between nitric oxide and abscisic acid in plant development and responses to stress. J. Exp. Bot. 65, 907-921. doi: $10.1093 / \mathrm{jxb} / \mathrm{ert} 454$

Lesage, G., and Bussey, H. (2006). Cell wall assembly in Saccharomyces cerevisiae. Microbiol. Mol. Biol. Rev. 70, 317-343. doi: 10.1128/MMBR.00038-05

Lombardo, M. C., Graziano, M., Polacco, J. C., and Lamattina, L. (2006). Nitric oxide functions as a positive regulator of root hair development. Plant Signal. Behav. 1, 28-33. doi: 10.4161/psb.1.1.2398

Mason, R. P. (2016). Imaging free radicals in organelles, cells, tissue, and in vivo with immuno-spin trapping. Redox Biol. 8, 422-429. doi: 10.1016/j.redox.2016.04.003

Mélida, H., Sandoval-Sierra, J. V., Diéguez-Uribeondo, J., and Bulone, V. (2013). Analyses of extracellular carbohydrates in oomycetes unveil the existence of three different cell wall types. Eukaryot. Cell 12, 194-203. doi: 10.1128/EC.00288-12

Miedes, E., Vanholme, R., Boerjan, W., and Molina, A. (2014). The role of the secondary cell wall in plant resistance to pathogens. Front. Plant Sci. 5:358. doi: $10.3389 /$ fpls.2014.00358

Mine, I., Yamasaki, T., Sekida, S., and Okuda, K. (2016). Measurement of cell wall thickness in the giant-celled xanthophycean alga Vaucheria frigida. Cytologia 81, 225-230. doi: 10.1508/cytologia.81.225

Nie, S., Yue, H., Zhou, J., and Xing, D. (2015). Mitochondrialderived reactive oxygen species play a vital role in the salicylic acid signaling pathway in Arabidopsis thaliana. PLOS ONE 10:e0119853. doi: 10.1371/journal.pone.0119853
Ochoa-Villarreal, M., Aispuro-Hernández, E., Vargas-Arispuro, I., and MartínezTéllez, M. Á. (2012). "Plant cell wall polymers: function, structure and biological activity of their derivatives," in Polymerization, ed A. D. S. Gomes (Rijeka: InTech), 63-86.

Pedersen, S. K., Holmehave, J., Blaikie, F. H., Gollmer, A., Breitenbach, T., Jensen, H. H., et al. (2014). Aarhus sensor green: a fluorescent probe for singlet oxygen. J. Org. Chem. 79, 3079-3087. doi: 10.1021/j0500219y

Peteu, S. F., Boukherroub, R., and Szunerits, S. (2014). Nitro-oxidative species biosensing: challenges and advances with focus on peroxynitrite quantification. Biosens. Bioelectron. 58, 359-373. doi: 10.1016/j.bios.2014.02.025

Petřivalský, M., Vaníčková, P., Ryzí, M., Navrátilová, B., Piterková, J., Sedlářová, M., et al. (2012). The effects of reactive nitrogen and oxygen species on regeneration and growth of cucumber cells from isolated protoplasts. Plant Cell Tissue Organ Cult. 108, 237-249. doi: 10.1007/s11240-011-0035-3

Popper, Z. A., Michel, G., Hervé, C., Domozych, D. S., Willats, W. G., Tuohy, M. G., et al. (2011). Evolution and diversity of plant cell walls: from algae to flowering plants. Annu. Rev. Plant Biol. 62, 567-590. doi: 10.1146/annurev-arplant-042110-103809

Popper, Z. A., Ralet, M. C., and Domozych, D. S. (2014). Plant and algal cell walls: diversity and functionality. Ann. Bot. 114, 1043-1048. doi: $10.1093 / \mathrm{aob} / \mathrm{mcu} 214$

Prasad, A., Sedlářová, M., Kale, R., and Pospíšil, P. (2017). Lipoxygenase in singlet oxygen generation as a response to wounding: in vivo imaging in Arabidopsis thaliana. Sci. Rep. 7:9831. doi: 10.1038/s41598-017-09758-1

Prats, E., Carver, T. L., and Mur, L. A. (2008). Pathogen-derived nitric oxide influences formation of the appressorium infection structure in the phytopathogenic fungus Blumeria graminis. Res. Microbiol. 159, 476-480. doi: 10.1016/j.resmic.2008.04.001

Qiao, W., Li, C., and Fan, L.-M. (2014). Cross-talk between nitric oxide and hydrogen peroxide in plant responses to abiotic stresses. Environ. Exp. Bot. 100, 84-93. doi: 10.1016/j.envexpbot.2013.12.014

Raja, V., Majeed, U., Kang, H., Andrabi, K. I., and John, R. (2017). Abiotic stress: interplay between ROS, hormones and MAPKs. Environ. Exp. Bot. 137, 142-157. doi: 10.1016/j.envexpbot.2017.02.010

Ruiz-Herrera, J. (1992). Fungal Cell Wall: Structure, Synthesis and Assembly. Boca Raton, FL: CRC Press.

Saxena, I., Srikanth, S., and Chen, Z. (2016). Cross talk between H2O2 and interacting signal molecules under plant stress response. Front. Plant Sci. 7:570. doi: 10.3389/fpls.2016.00570

Schmitt, F.-J., Renger, G., Friedrich, T., Kreslavski, V. D., Zharmukhamedov, S. K., Los, D. A., et al. (2014). Reactive oxygen species: re-evaluation of generation, monitoring and role in stress-signaling in phototrophic organisms. Biochim. Biophys. Acta 1837, 835-848. doi: 10.1016/j.bbabio.2014.02.005

Sedlářová, M., Kubienová, L., Drábková Trojanová, Z., Luhová, L., Lebeda, A., and Petřivalský, M. (2016). The role of nitric oxide in development and pathogenesis of biotrophic phytopathogens - downy and powdery mildews. Adv. Bot. Res. 77, 263-283. doi: 10.1016/bs.abr.2015.10.002

Sedlářová, M., Petřivalský, M., Piterková, J., Luhová, L., Kočírová, J., and Lebeda, A. (2011). Influence of nitric oxide and reactive oxygen species on development of lettuce downy mildew in Lactuca spp. Eur. J. Plant Pathol. 129, 267-280. doi: 10.1007/s10658-010-9626-9

Sinha, R. K., Komenda, J., Knoppová, J., Sedlářová, M., and Pospišil, P. (2012). Small CAB-like proteins prevent formation of singlet oxygen in the damaged Photosystem II complex of the cyanobacterium Synechocystis sp. PCC 6803. Plant Cell Environ. 35, 806-818. doi: 10.1111/j.1365-3040.2011. 02454.x

Thordal-Christensen, H., Zhang, Z., Wei, Y., and Collinge, D. B. (1997). Subcellular localization of $\mathrm{H} 2 \mathrm{O} 2$ in plants. $\mathrm{H} 2 \mathrm{O} 2$ accumulation in papillae and hypersensitive response during the barley-powdery mildew interaction. Plant J. 11, 1187-1194. doi: 10.1046/j.1365-313X.1997.110 61187.x

Tian, J., Chen, H., Zhuo, L., Xie, Y., Li, N., and Tang, B. (2011). A highly selective, cell-permeable fluorescent nanoprobe for ratiometric detection and imaging of peroxynitrite in living cells. Chem. Eur. J. 17, 6626-6634. doi: $10.1002 /$ chem. 201100148

Vandelle, E., and Delledonne, M. (2011). Peroxynitrite formation and function in plants. Plant Sci. 181, 534-539. doi: 10.1016/j.plantsci.2011.05.002 
Wanders, R. J., Waterham, H. R., and Ferdinandusse, S. (2016). Metabolic interplay between peroxisomes and other subcellular organelles including mitochondria and the endoplasmic reticulum. Front. Cell Dev. Biol. 3:83. doi: $10.3389 /$ fcell.2015.00083

Wojtaszek, P. (1997). Oxidative burst: an early plant response to pathogen infection. Biochem. J. 322(Pt 3), 681-692. doi: 10.1042/bj3220681

Yuan, L., Lin, W., Xie, Y., Chen, B., and Zhu, S. (2012). Single fluorescent probe responds to $\mathrm{H} 2 \mathrm{O} 2$, $\mathrm{NO}$, and $\mathrm{H} 2 \mathrm{O} 2 / \mathrm{NO}$ with three different sets of fluorescence signals. J. Am. Chem. Soc. 134, 1305-1315. doi: 10.1021/ja2 100577
Conflict of Interest Statement: The authors declare that the research was conducted in the absence of any commercial or financial relationships that could be construed as a potential conflict of interest.

Copyright (c) 2017 Sedlářová and Luhová. This is an open-access article distributed under the terms of the Creative Commons Attribution License (CC BY). The use, distribution or reproduction in other forums is permitted, provided the original author(s) or licensor are credited and that the original publication in this journal is cited, in accordance with accepted academic practice. No use, distribution or reproduction is permitted which does not comply with these terms. 